\title{
Yale Meets Its Catalog
}

Miss Field is assistant head cataloger in charge of the Serial Department, and wrote the section on the interfiling project; Miss Hitchcock is senior cataloger and research assistant, Yale University Library.

$\mathrm{T}$ HE Yale staff has recently worked through its public catalog from $A$ to $Z$ on three projects. The Yale catalog is large - four thousand trays, four million cards. Often it is felt that a large catalog is too big to change or manipulate. Sometimes immutability is enshrined as the essential quality of a large or old catalog. Yale's recent projects offer evidence that size is not an insurmountable obstacle, that changing conditions necessitate new decisions, and that systematic work on the whole catalog can be a vitalizing experience.

In 1947-48 the Catalog Department read through the public catalog and listed the subject headings. In 1948 the Serial Department interfiled the public serial cata$\log$ with the main public catalog. In 1948 49 the professional staff from various departments selected entries to be filmed for the National Union Catalog of the Library of Congress.

\section{SUBJECT PROJECT}

\section{Evolution of the Subject File}

An official subject list was not a new idea at Yale in 1947, but in that year the idea was reshaped and translated into action.

In 1907 when Yale changed from an alphabetical-classed to a dictionary catalog, a list was made of the subject headings then in use. This list was abandoned almost immediately because the policy of following Library of Congress headings was inaugurated. In the next two decades there was a mass conversion to Library of Congress headings while the $2^{\prime \prime} \times 5^{\prime \prime}$ cards of the old catalog were being replaced by standard size cards and while books were being reclassed from the old numbered shelves. During this period and thereafter, the Library of Congress list was used as authority for headings although it was never systematically annotated for Yale practice. It was used in conjunction with the catalog and small desk files were built up by individuals for convenient operation in the work of their special subject fields.

This arrangement was tenable until 1930 when the library moved into a new building where the catalogers are a block away from the public catalog. In the following years there was a growing awareness not only that a complete list of headings was desirable in the Catalog Department, but also that the only way to record headings and subdivisions not enumerated in the Library of Congress list and to gather up Yale headings-remnants of pre-1907 subjects and conscious deviations from $\mathrm{Li}$ brary of Congress practice-was to read through the Yale catalog.

In 1947 simultaneous recommendations for an official subject list were made to the librarian in a report on a survey of technical processes at Yale by Wyllis E. Wright, librarian of Williams College, and in the second annual report of the new head of the Catalog Department. Work started in July, and in the following April a 
subject file of some 71,500 cards was a reality.

\section{Complementary Work-Authority Cards for Official Catalog}

When the library moved into the new building, an official catalog of author entries was $\operatorname{made}^{1}$ for the convenience of the processing departments. This was placed in the Catalog Department. Author entries for serials were included only if the author heading was not represented in the official catalog by another publication, since an official serial catalog was made for the Serial Department at the same time. Subject entries were not reproduced as it was considered too expensive, both in cost of dexigraphing and in space for housing; but any potential author heading (e.g., the name of a biographee not yet used as an author in the catalog) was represented by dexigraphing one of the cards under the heading.

Thereafter, whenever a new author heading was established in serial or subject work, it was recorded in the official catalog by means of a unit card from the set being made on that occasion. Authorities and references were traced on the catalog card involved. This procedure was used to build up and maintain the official catalog as the single tool for checking author headings rather than the customary authority card routine.

The system of recording, in the official catalog, subject entries that were potential author headings brought the subject file and official catalog into juxtaposition as complementary authority files. In the initial foray on reading the public catalog for the subject project, the general directive was to select all headings used as subjects except those represented in the official cata-

1 Monrad, Anna M. "The Use of the Dexigraph in Making an Official Catalog." Library Journal 57:218-22, March 1932 . log. There was a little vagueness about which subject headings had gone in the official catalog as potential authors, and soon came the poignant query "What is a subject?"

The exhumed 1930 dexigraphing rules stated that expeditions, abbeys, ships, gods, streets, monuments, shrines and runic inscriptions were included in the official catalog. A little more exploration and discussion disclosed that independent judgments, lapses of memory and the intervening years had taken their toll in consistency. Superimposed on this unsettled situation was the problem of dealing with a gamut of statues, houses, manors, castles, cathedrals, theaters, railroads, canals and parks, which generally are not authors or potential authors but which in a pedantic person's imagination conceivably could be. There were also fictitious and mythological characters, animals and deities which, judged by the words in the headings (e.g., Bunyan, Paul; Bucephalus; Diana), would seem to be authors to the less literate. On the borderline of the subject side were names of families, royal houses, tribes, peoples, treaties, alliances, battles and events.

The problem of debatable subject headings resulted in two major decisions not contemplated in the recommendations for a subject file. One was to list geographical names and quasi-authors (even though actually subjects) in the official catalog. The other was to do such listing on colored card stock.

Place names used only as subjects had not been dexigraphed for the official cata$\log$ in 1930; and the listing of names of places and geographical features was a desideratum, twin to the listing of pure subjects, of the subject project as originally conceived. Consideration of geographical names and quasi-authors as a common problem made it seem more reasonable, how- 
ever, to have all headings allied to author headings in the official catalog.

Names of families, royal houses, etc., remained the property of the subject file. The subject subdivisions of author headings also are in the subject file.

The necessity of keeping both files intact in the future by making for any new subject either a subject file card or an authority card for the official catalog introduced the idea of authority cards for author headings. In the new routine authority cards are not made for all author headings but only when it is necessary to trace references or represent in the official catalog a heading established for use as an entry in some other catalog.

The authority card routine, which came along as a natural complement to the subject file, stands as an achievement almost as desirable as the subject file itself. Its appearance illustrates the repercussion on old routines which can follow the introduction of a new routine.

\section{Coordinated Work-Place Name Editing}

The subject project provided an unexcelled opportunity to do editorial work on subdivisions under names of countries and states that had never been changed to Library of Congress form or modernized since 1907 . It was obviously desirable to do such editing before the headings were copied, and the need for changes had been considered several times.

The responsibility for the work fell on the catalogers in the history and geography classes. Bulk work was done by assistants in the geography class on date subdivisions under the subdivision Descr. छ trav. Dates specific to the content of the book were cancelled if there were less than 25 cards under the subdivision; if more, they were changed to broad period dates, usually a century, or half-century, but for some very large files even a quarter-century.

Similarly, dates specific to the content of the book which had been used under the subdivisions For. rel., Hist., Military hist., Naval hist., and Pol. छ govt. were abolished or changed to the conventional historical period dates that have been established by the Library of Congress.

The subdivision Maps under Descr. E trav. was changed to a direct subdivision under locality.

Subdivisions under place names with less than five subject cards were usually abolished.

Army and Navy headings were referred to the military science cataloger for change to the vernacular in accordance with the new Library of Congress practice.

These and other minor changes were handled in the daily routine of the project and provided a dramatic example of editorial work that can be done in the future.

\section{Routine and Statistics of the Project}

Accuracy demanded direct copying from the public catalog trays. Removing trays from the public catalog was felt by the Reference Department to be too much of a handicap during the busy afternoon period, so a procedure was built up that would revolve through its complete cycle within the morning hours each day.

The personnel was divided into three corps: clippers, carders and editors. The clippers were catalogers, of all levels of experience, who read the trays for subject headings and inserted paper clips on the cards to be copied-on the top for cards for the subject file, and on the side for cards for the official catalog. Their work started at the beginning of each morning and was followed by the place-name editing. The carders were typists who copied the headings from the clipped cards in the manner designated by the clippers-on waste 
cards for the subject file or on colored stock for the official catalog, with a card for each heading and subdivision or several subdivisions on one card. The editors were catalogers who did the proofreading of the copying, added descriptive phrases to indicate the nature of unfamiliar terms, and recorded the class numbers of subjects which appeared to have specific classes.

The few figures tabulated here give an idea of the expense of the project in hours, the relation of the hours to the number of trays in the Yale catalog and the number of cards made:

Large subjects and countries

Hours Trays

Preliminary procedures

Final routine:

$3,120.0 \quad 3,247$

$\begin{array}{lr}\text { Clipping } & 698.5 \\ \text { Carding } & \text { I } 134.0 \\ \text { Editing } & 796.8 \\ \text { Supervision } & 490.7\end{array}$

Total

Cards made:

Headings and references

for subject file

Headings for official catalog:

$4,275.2 \quad 3,891$

Geographical names 9,000

Quasi-authors

3,720

References for official catalog

Total

The peak production weeks ran at a speed of 40-odd trays a morning with nine clippers, two place name editors, 13 carders and four editors. The average production rate for all processes of the entire project was $2 \mathrm{I}$ cards per hour.

\section{INTERFILING PROJECT}

The interfiling of the separate public serial catalog with the main public catalog was another major project undertaken.
Yale has always considered it desirable to maintain in the public catalog a record of its holdings in serial sets. Up to 1918 this was done by pencilled notations on the main entry for each serial. In that year the library decided to use check cards for listing holdings and to file these with the main entries in a separate serial catalog, which was established in order to have a working tool for the staff and to make the finding of serial entries easier for the public. Cards in the main public catalog became skeleton entries, without holdings or notes, referring readers to the serial catalog for full information. Both the serial and main catalogs contained all main entries, added entries and references for serials; but subject cards were filed only in the main catalog.

It should be made clear at this point that, when the separate serial catalog was set up, the Serial Department ceased making any record of serial holdings in the shelflist. Since Yale has never used accession numbers, these did not have to be recorded; and the serial catalog, therefore, became the only detailed record of serial holdings in the library.

With the transfer to the new library building in 1930 it became necessary, because of the distance of the Serial Department from the public catalog, to develop an official serial catalog for the use of the staff. This was accomplished by dexigraphing the separate public serial catalog in its entirety, and at this point the traveling card system was inaugurated to keep the record of holdings in the public catalog up to date.

The system of two separate serial cata$\operatorname{logs}$, plus cards in the public catalog referring to the serial catalog, was maintained until 1948. Early in that year the new head of the Serial Department proposed to the library administration that the public serial catalog be interfiled with the 
main public catalog. The chief reasons for such a move were:

I. The advantage to the public of being able to find all publications in the library in one alphabetical file.

2. The advantage to the public of being able to find the fullest information about all serials in the catalog first consulted. Since readers could not always know that what they were seeking was a serial, they wasted much time by not knowing in which catalog to look first. Also, Yale's practice in cataloging monograph series, whether classified separately or together, was to give the fullest information in the main public catalog, since the analytical cards and the series added entries were filed there. The result again was that one could not tell in which catalog to look first.

3. The elimination of thousands of duplicate cards both at that time and in the future. The immediate reduction would give the library much needed space for expansion of its public catalog. The time required for typing and filing all of these duplicate cards would be saved in the future.

4. Fewer cards to withdraw and correct in recataloging.

5. The congestion in the alcove where the public serial catalog was housed. This was a situation that could be relieved only by spreading out the catalog.

6. With only one public catalog the Serial Department could initiate brief cataloging and form cards for minor serials; this had been held up for years because of the complications involved in having to refer back and forth between two catalogs.

7. The Serial Department now had its working tool in its own official serial cata$\log$ and did not need a separate public serial catalog for this purpose.

This analysis of the situation by the Serial Department was further borne out by the survey of technical processes made by $M r$. Wright, already referred to in this paper, in which he had also recommended this move. The proposal was discussed with the department heads and with the University Library Committee, composed of faculty and administrative officers, before the decision was made to proceed with the interfiling.

In August 1948 the Serial Department started the interfiling, which meant substituting the main entries with holdings and notes and the added entries from the serial catalog for the equivalent skeleton cards in the public catalog that referred readers to the serial catalog. Certain types of entries which were duplicated exactly in the public catalog (e.g., closed entries, see references from one author heading to another, etc.) were first removed by clerical assistants in the department in order to save the interfilers the time of handling them. The serial catalogers worked in shifts on the interfiling, withdrawing any cards which showed discrepancies between the two catalogs for later attention. The interfiling took just over seven weeks, and in the process slightly more than 187,000 cards were discarded.

\section{Monograph Series}

The interfiling itself did not finish the work for the Serial Department. There remained the problem of changing the form used for recording classed-together monograph series. Yale had followed the practice used in many libraries of making a series added entry for each volume of the series. These were filed in the main public catalog. In the public serial catalog there had been holdings cards showing which volumes had been received; and, since the volumes had been added to these cards at the time they came into the library, they had been recorded in the public serial cata- 
log long before the analytics and series added entries for them had been filed in the main public catalog. The Serial Department recommended that the monograph type of holdings card (Fig. I) be substituted for these series added entries in the public catalog.

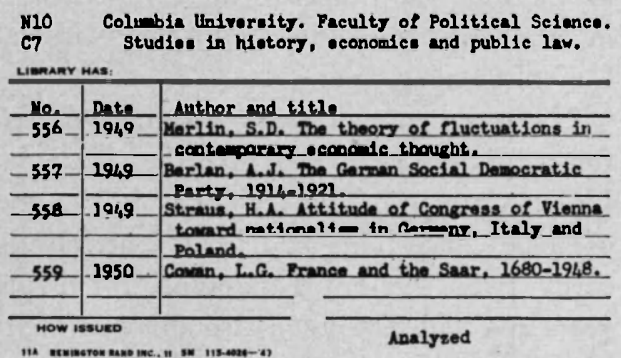

FIG. I. Monograph holdings card substituted for series added entries in public catalog. This type of card was planned and put into use in the early 1940's by the former head of the Serial Department, Grace P. Fuller.

The proposal was limited to changing the form for current sets only. Although changing all monograph series, including those which had ceased publication and those of which Yale had only scattered files, would have made the system uniform and would have resulted in the elimination of a much larger number of cards from the public catalog, this task seemed an impossible one for the department to undertake. This tremendous project was started shortly after the interfiling was finished. It went much more slowly than the interfiling, since it had to be done along with current work; but it was finally finished in January 1950. Since, on the average, one holdings card was substituted for every five series added entries, the public catalog was reduced by about 17,500 cards.

Series added entries for classed-together monograph series had been filed in the official catalog in the Catalog Department as well as in the public catalog. All such cards were removed from this catalog, which eliminated approximately 65,000 cards more, making a total reduction of 82,500 cards from the catalogs of the library.

This entire project of interfiling and changing the form for monograph series resulted, therefore, in the elimination of 270,000 cards from the catalogs of the library. The saving in cards needed for the public catalog in the new setup and the simpler typing forms that the Serial Department was enabled to put into effect because of having only one catalog for the public reduced the amount of time required for typing sets of serial cards to the extent of one full-time typist, and there was no longer a separate public serial catalog requiring filing and maintenance by the department.

The interfiling also accomplished the original objectives of making it possible for readers to find all publications in one cata$\log$ and of dispersing the congestion at the public serial catalog.

The chief difficulty experienced since the interfiling has seemed to be the inability of some readers to find such periodicals as Time, Life or Education, which are now filed after subjects and before other titles beginning with the same word. The insertion of additional guide cards is expected to obviate this difficulty.

\section{Subsidiary Benefits}

There were several subsidiary benefits derived from the reworking of the classedtogether monograph series. It was inevitable that the serial catalogers should discover that many volumes which were supposed to be analyzed never had been done. The Catalog Department cooperated to the fullest extent in clearing up these arrears in analyzing so that, by the time the Serial Department had completed its 
work on this project, the catalog was up to date in this respect.

Furthermore, there were many analyzed series which, in the light of present-day policies, would not be analyzed at all. Some of these were de-analyzed, and for others the decision was made not to analyze in the future. The Reference Department was consulted frequently in deciding about these series and was very helpful in this respect.

Another gain was that, in going over the entire serial catalog from $A$ to $Z$, the serial catalogers found and straightened out many inconsistencies between serial and monograph cataloging that had crept in during the years. With only one public cata$\log$ now, the likelihood of these going undiscovered in the future will be much less.

\section{UNION CATALOG PROJECT}

In the winter of $1947-48$ the chief of the Union Catalog Division of the Library of Congress and the librarian of Yale decided that the time had finally come when it would be possible to record in the $\mathrm{Na}$ tional Union Catalog titles held by Yale. A new method of microfilm reproduction was available which did not require manual copying by a W.P.A. or other nonexistent corps. The chief of the Union Catalog Division, after having inspected the Yale catalog, was convinced that a properly selected half-million titles would adequately represent Yale's holdings for the purposes of the National Union Catalog and felt that his staff, somewhat increased after the depression years which fell on the heels of the golden Project B days, could integrate that number of cards into the Union Catalog. The librarian of Yale was willing to let the Yale staff do the selection part of the project in order to contribute to the National Union Catalog the listing of Yale's vast research materials.
The rules for selecting the titles for this particular project were drawn up by the chief of the Union Catalog Division and by the head of the Catalog Department of Yale. They worked together during a visit of the former to Yale and through correspondence verified tentative decisions by checking the results as the cards selected in trial runs were filed into the National Union Catalog.

Naturally enough, titles were not selected for cards already sent to the National Union Catalog. There were some 162,000 of these, since Yale had been contributing cards from current cataloging for many years and had sent down also an extra shelflist of titles in the Rare Book Room and a card file of material in the Russian language, both of which files had been discontinued. In anticipation of the project and after the scope of cards contributed to the Union Catalog on a current basis had been enlarged in 1943, the main entry cards in the public catalog had been stamped "CDU made." These cards were omitted easily enough in the selection process, granted sufficient concentration, as were L: C. cards for which Yale had supplied copy for printing. Recognition of entries sent before 1943 was the trickiest part of the selection process. In general, all mimeographed cards were omitted, because since I939 an extra card had been run off for the Union Catalog for any mimeographed set of cards; and this method of duplication had been installed at Yale only a few years prior to 1939.

The other categories of material not selected were titles believed to be already in the National Union Catalog with locations from a sufficient number of libraries or titles that could be located through other finding lists. These categories were: American copyright imprints after 1899; American imprints $1800-1899$ on L.C. printed 
cards; L.C. printed cards for foreign hooks in a series; serials; page analytics and reprints except dissertations; single maps; sheet music; incunabula; documents of the United States, all states except Connecticut, and all cities except New Haven, and documents of large foreign countries; congressional speeches; law reports; material being allocated to Yale's possible storage collection; unimportant pamphlets; and variant editions when place, publisher and pagination were alike.

The selection process required professional people who would understand the reasoning behind the bases for selection, who could read the cards in the Yale cata$\log$ quickly and recognize the kind of material represented by them. Although Yale was willing to donate the time of professional staff to promote the value and use of the National Union Catalog, nevertheless, it was recognized that this would be expensive. To make the most of the time spent thumbing through cards, various other pieces of work were included from which Yale would realize profit for itself.

Titles of books in the stacks that would be candidates for the Rare Book Room according to recently accepted dates for potential rarity were noted on slips, and the slips (about I80o) were sent to the librarian of the Rare Book Room. Cards for maps and manuscripts were removed from the catalog, because although for several years they had been filed only in separate catalogs for maps and manuscripts, there had been no systematic gleaning of cards made for the public catalog before the separate catalogs were started. Some 9400 cards for A.L.A. page analytics, no longer useful, were removed from the catalog. Certain changes in filing were uniformly put in force, which otherwise would have been left for the filers to change whenever, and if ever, they encountered the cards filed according to older rules. Cooperation with the serial interfiling project was extended by crossing out stamps on subject cards containing the now obsolete phrase "See Serial Catalogue." Alert eyes also accumulated $10 \frac{1}{2}$ " of temporary slips which had not been pulled by the filers for one reason or another when the permanent cards were filed.

The selection of entries to be filmed for the National Union Catalog and the removing or editing of cards in the Yale catalog for Yale's own benefit was done by 24 of the professional staff from all departments in the library. The cards to be filmed were turned up in place in each tray; and the trays were placed on a truck at the filming machine, which was set up by the public catalog so that the trays were never unavailable to the public. The filming was done by high school assistants, student and clerical help. Since the filming went much faster than the selecting, there was a preponderance of professional staff used.

The microfilm camera was provided by the Library of Congress and was a Remington Rand, 16 millimeter. The rolls of film were mailed to Remington Rand who developed them. The enlargement prints were made by the Library of Congress Photoduplication Service, and these when cut and punched by the Union Catalog Division staff produced $3^{\prime \prime} \times 5^{\prime \prime}$ card size stock.

The number of titles selected totaled about 600,000 . This was a formidable amount to be absorbed by the National Union Catalog staff; but the combination of mechanical copying and judicious selection of entries made it an easy task for them compared to their previous arduous labor on the Philadelphia and Cleveland union catalogs, which had been sent to Washington tray by tray and literally compared and copied by typewriter. 
A study made during one of the trial runs with about 1400 cards showed that 32 per cent were titles new to the Union Catalog, 25 per cent were second locations and only 8 per cent were already there with six or more locations. A later sample with a much larger number of cards $(13,000)$ and a definition of a "new" title as one not represented by any edition showed but 7 per cent of new titles. A third test was made which helps comparison of the 32 per cent figure of the first test, which included other editions, with the 7 per cent figure of the second test. In the third test (with about I 600 cards), there were 19.4 per cent new titles exclusive of other editions and 10.5 per cent of new editions, which make a total of 29.9 per cent to compare with the 32 per cent of the first test.

The 600,000 titles filmed in the project and the 162,000 entries previously sent down have contributed to the National Union Catalog a total of 750,000 selected titles of important books possessed by Yale.

\section{CONCLUSION : PERIODIC CHANGES IN A LARGE CATALOG}

The common feature of the three projects was the subordination of the size of the catalog to other aspects of problems involving the catalog. The size of the catalog as a factor in the amount of work to be done could hardly be ignored, but it was a factor viewed dispassionately and then treated by allocating many people to the work.

The physical handling of a large catalog is a matter of quantity. A thousand hours is a total of roo hours from Io people, or 50 hours from 20 people. A large staff can work through a large catalog as easily as one or two persons can work through a small catalog if there is coordination and mutual understanding.
It is interesting and perhaps significant to note that the thousands of hours spent on the catalog in the three Yale projects did not overburden the staff or bog down other work. On the contrary, the annual statistics for output of regular cataloging in those years showed an increase. This may have been because of new routines and personnel; but it might well have resulted entirely, or partially, from an additional surge of energy springing from the spirit of accomplishment in pushing through the projects.

Certainly there is something exciting about a piece of work which moves rhythmically through a catalog from $A$ to $Z$. Progress is tangible. $Z$ will be the end, and $M$ the halfway point. This produces a dynamic mood, in retrospect at least, not induced by the cataloger's ordinary desk view of endless uncataloged books, with a void as the only concrete manifestation of completed work. The catalog is seen as a whole, which again is an invigorating contrast to the erratic approach afforded by checking here and there in the normal day's work. The policies and technical prowess of preceding librarians and catalogers can be absorbed as a whole picture. It is doubtful, however, if any project not accepted by the staff as a worthwhile objective would leave a feeling of satisfaction and an urge to start on a new program of concerted action. Nor would a poorlv made catalog be an inspiration.

In this connection may be pointed out a difference in effect, on staff and on the catalog, between a casual decision and a project decision. If a policy is instituted or changed without much discussion or without consideration by all persons involved, it is hard to put across the change in routine. A memorandum directive is not always remembered and followed when the points in question eventually appear in 
the daily work; hence, changes may be applied unevenly or lackadaisically.

There is something insidious about casual small changes in a large catalog. Minor alterations applied gingerly can do more to deform a catalog than a clear cut master blow that strikes the entire catalog at once. Unadvertised changes catch people unawares, for the cards in the catalog do not proclaim by whom and under which rules they were made. This applies even more forcefully to altered policies in the production of cards for the catalog. Cards not made and information not put on cards never can be found in the catalog, and no editing of the catalog without the books in hand can ever supply what was never done. It seems better to let a catalog grow uniformly and then cut it back or trim it out at periodic intervals according to a stated library-wide policy after a long period of deliberation than to maim and distort it with a blight of small economies or pseudobrilliant ideas introduced intermittently on tiny segments.

A project decision has the attention of everybody at once. A sizeable expenditure of time, blocked out as such, will not be granted until competent advice has approved it. The staff as a whole carries out the decision and is concentrating on all the attendant problems. This is important in a large library, for the problem of the size of the catalog is not purely a matter of quantity. The quality of the catalog springs from the intricacies of its design for answering manifold questions for multifarious purposes. It takes many people with various points of view and active contact with the catalog and all parts of the work of the library to pursue adequately the ramifications of the purposes and design of the catalog. The real difficulties in handling a large catalog are the analysis of the needs of readers with diverse per- sonalities and purposes and the integration of a large staff with special talents and duties. The physical size of the catalog is not the major problem.

These are a few observations and reflections that have come from the projects on the Yale catalog. It was an opportunist imagination that seized the chance to edit the catalog while listing headings for the subject file and while selecting entries for the National Union Catalog. The venture was so successful that it seems quite possible now as a normal course of action to build up consciously a list of desired changes to be put into effect at periodic intervals instead of leaving change to chance.

Such a system would encourage the individual staff member to contribute isolated suggestions which, together with ideas picked up at random or otherwise from readers, can be accumulated, coordinated and developed into a larger policy. Action would not necessarily have to follow on the heels of decision but could wait along with other approved changes for the next editing project on the catalog. This would provide time for retrospective confirmation of decisions. The project pool for periodic editing of the catalog should be limited to changes requiring systematic $A-Z$ work on the catalog, illustrated in the Yale projects by the editing of place-name subdivisions and the removal of cards for maps and manuscripts. The editing would be done by as many people as possible and thereby quickly completed without undue interruption of normal work.

If there is a sound basis for desiring a change, there seems to be no reason for not making it. A catalog, even though large, is not impossible to handle. A change is not too expensive if the result is future economy; or is it unnecessary if the outcome is better service to readers. 